\title{
ABDUCENS NERVE PALSY AND THROMBOSIS OF THE CEREBRAL VEINS AND SINUSES - A DIAGNOSTIC PITFALL
}

\author{
Alexandra J. Tzoukeva ${ }^{1}$, Ara G. Kaprelyan ${ }^{1}$, Valeria Kaleva ${ }^{2}$, Chavdar Bachvarov ${ }^{3}$, \\ Radoslav Georgiev ${ }^{3}$, Elina Peteva ${ }^{2}$. \\ 1) Department of Neurology, 2) Pediatric Department, 3) Department of \\ Radiology, \\ University Hospital St Marina, Varna, Bulgaria
}

\begin{abstract}
Thrombosis of the cerebral veins and sinuses is an infrequent cerebrovascular disorder. Because the highly variable symptoms, recent neuroimaging plays a key role in the diagnosis. Abducens nerve palsy as a focal neurological deficit is a rare clinical manifestation in these patients. We present two cases with sudden onset of diplopia and headache.

Case 1: A 3-year old girl with B cell lymphoblastic leukemia developed bilateral abducens deficit and bilateral optic disc edema after treatment including L-asparaginase. Thrombosis of the right jugular vein, sagittal and right sigmoid sinuses was visualized on magnetic resonance imaging (MRI) and magnetic resonance venography (MRV). Symptoms gradually resolved after treatment with enoxiparine and MRV demonstrated recanalization.

Case 2: A 75-year old female with medical history of arterial hypertension presented with headache and sudden left abduction deficit. Computerized tomography (CT) scan was normal. MRI and MRV revealed aging brain and disruption of venous flow at the left internal jugular vein, suspecting thrombosis. Extracranial colour duplex sonography and CT angiography proved haemodinamic equivalent of left internal jugular vein thrombosis due to sclerotic pathology of aortic arch.

Our first case illustrates the role of improved neuroimaging techniques as the best method for diagnosis of cerebral veins and sinuses thrombosis, presenting with abducens nerve palsy. With second case the potential neuroimaging pitfalls concerning the accurate diagnosis of these cerebrovascular disorders with neuro-ophthalmologic manifestation are discussed.
\end{abstract}

Key words: abducens nerve palsy, cerebral veins and sinuses thrombosis, diagnostic pitfall

\section{INTRODUCTION}

Thrombosis of the cerebral veins and sinuses is an infrequent cerebrovascular disorder. Prothrombotic risk factors or direct causes are often identified, e.g. oral contraceptives, L-asparaginase, head injury, lumbar punction, systemic or local infections (otitis, mastoiditis) (2, $3,4,6,8,10,11,12,15)$. The most frequent, but least specific clinical symptom of cerebral veins and sinus thrombosis, is severe headache. The neurologic stroke-like signs depend on the cerebral lesion's localization, as well as the adequacy of venous collateral circulation: hemiparesis, aphasia, seizures, delirium, amnesia, mutism, coma and eye symptoms (periorbital edema, proptosis, chemosis, and paralysis of eye movements) $(5,14)$. Abducens nerve palsy, as a focal neurological deficit, is a rare clinical manifestation in these patients $(7,9)$. Isolated intracranial hypertension is characterized by headache with diplopia due to sixth nerve involvement and funduscopic presentation of papilledema. Because the highly variable symptoms, recent neuroimaging plays a key role in the diagnosis. Potential diagnostic and technical pitfalls related to image interpretation are discussed in the literature $(1,13)$. The best treatment options are anticoagulation to arrest the thrombotic process and dehydration to reduce the intracranial pressure (i.e. diplopia and papilledema) $(5,14)$.

We present two cases with sudden onset of diplopia and headache.

\section{CASES REPORT}

\section{Case 1.}

A 3-year old girl with one day headache and horizontal diplopia was presented at our neuroophthalmological section. She had a medical history of precursor B cell lymphoblastic leukemia without CNS involvement. Treatment according to the ALL BFM 2000 protocol, including L-asparaginase was started. A remission was registered. During the final of the first induction phase she suffered sudden headache and double vision. Neuroophthalmological examination showed bilateral abducens nerve palsy and funduscopy revealed bilateral optic disc edema. The coagulation state showed markedly elevation in factor VIII, but without presence of thrombophilic defects; 
antithrombin III and protein C levels were within the normal range. Brain imaging was performed to look for possible intracranial complication of leukemia as the cause of neuroophthalmological manifestation. Thrombosis of the right jugular vein, sagittal and right sigmoid sinuses was visualized on magnetic resonance venography (MRV) (fig. 1) and computerized tomography venography (CTV) (fig. 2). Symptoms gradually resolved after treatment with IV infusions of mannitol and SC low molecular weight heparin injections. CTV demonstrated recanalization one month later (fig. 3).

\section{Case 2.}

A 75-year old female with medical history of arterial hypertension presented with headache and sudden double vision. Neuro-ophthalmologic examination showed abducens deficit in the left eye and intact other cranial nerves; normal visual acuity and Humphrey visual field test bilaterally; dilated funduscopy was within normal limits. MRV revealed aging brain and disruption of venous flow at the left internal jugular vein, suspecting thrombosis (fig. 4). Extracranial colour duplex sonography and CTV proved haemodinamic equivalent of left internal jugular vein thrombosis due to sclerotic pathology of aortic arch (fig. 5). Ischemic nature with atherosclerotic comorbidity of abducens nerve palsy was discussed. Adequate vascular therapy was administered. The left abducens palsy recovered gradually and two months later she had normal ocular movements.

\section{DISCUSSION}

Most isolated abducens nerve palsies are ischemic in nature. However there are other causes which require aggressive diagnostic and therapeutic management $(7,9)$. Thrombosis of the cerebral veins and sinuses, with highly variable symptoms and causes, most often affects young adults and children, but about $75 \%$ of the adult patients are women $(3,4,6,8,10)$. All these patients with isolated intracranial hypertension have headache with diplopia, due to involvement of the sixth nerve, and papilledema on funduscopic testing $(5,14)$. The most sensitive examination techniques, leading to the correct diagnosis in these cases, are MRI, MRV, and CTV, but expert radiologic judgment is required to avoid diagnostic and technical pitfalls $(1,13)$. The accurate diagnosis helps to determine the more effective treatment and to improve the disease prognosis $(9,11,15)$. In our first case it was important for the management and prognosis to identify the abducens nerves palsy and papilledema as symptoms of CNS involvement of the leukemia or as signs of veins and sinuses thrombosis, following L-asparaginase therapy. The exact imaging interpretation in the second case, revealed the appropriate therapeutic procedures.

\section{CONCLUSION}

Our first case illustrates the role of improved neuroimaging techniques as the best method for diagnosis of cerebral veins and sinuses thrombosis, presenting with abducens nerve palsy. With second case the potential neuroimaging pitfalls, concerning the accurate diagnosis of these cerebrovascular disorders with neuro-ophthalmologic manifestation are discussed.

Fig. 1. Magnetic resonance venography: thrombosis of the right jugular vein, sagittal and right sigmoid sinuses.
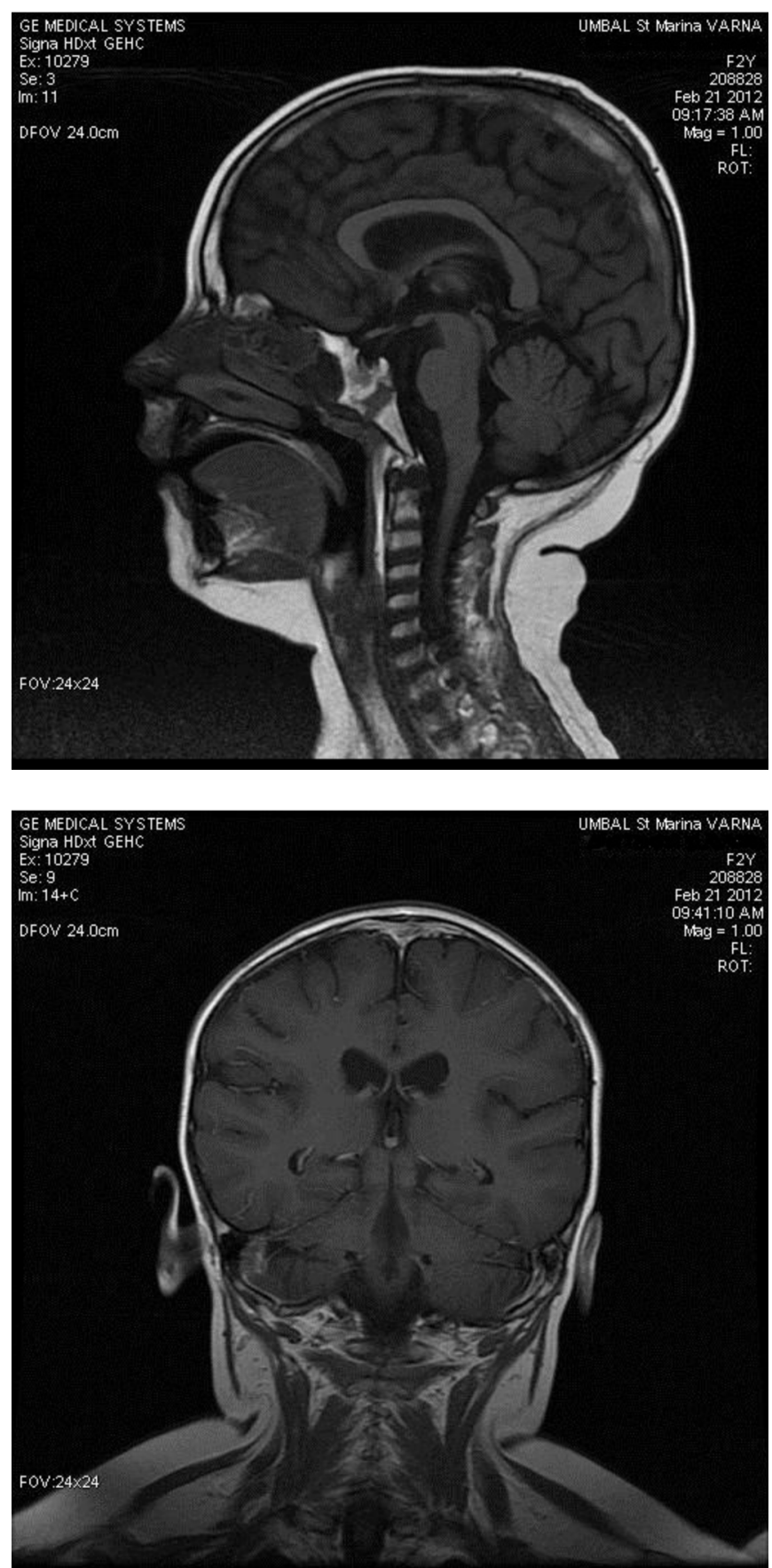
Fig. 2. Computerized tomography venography: thrombosis of the right jugular vein, sagittal and right sigmoid sinuses.
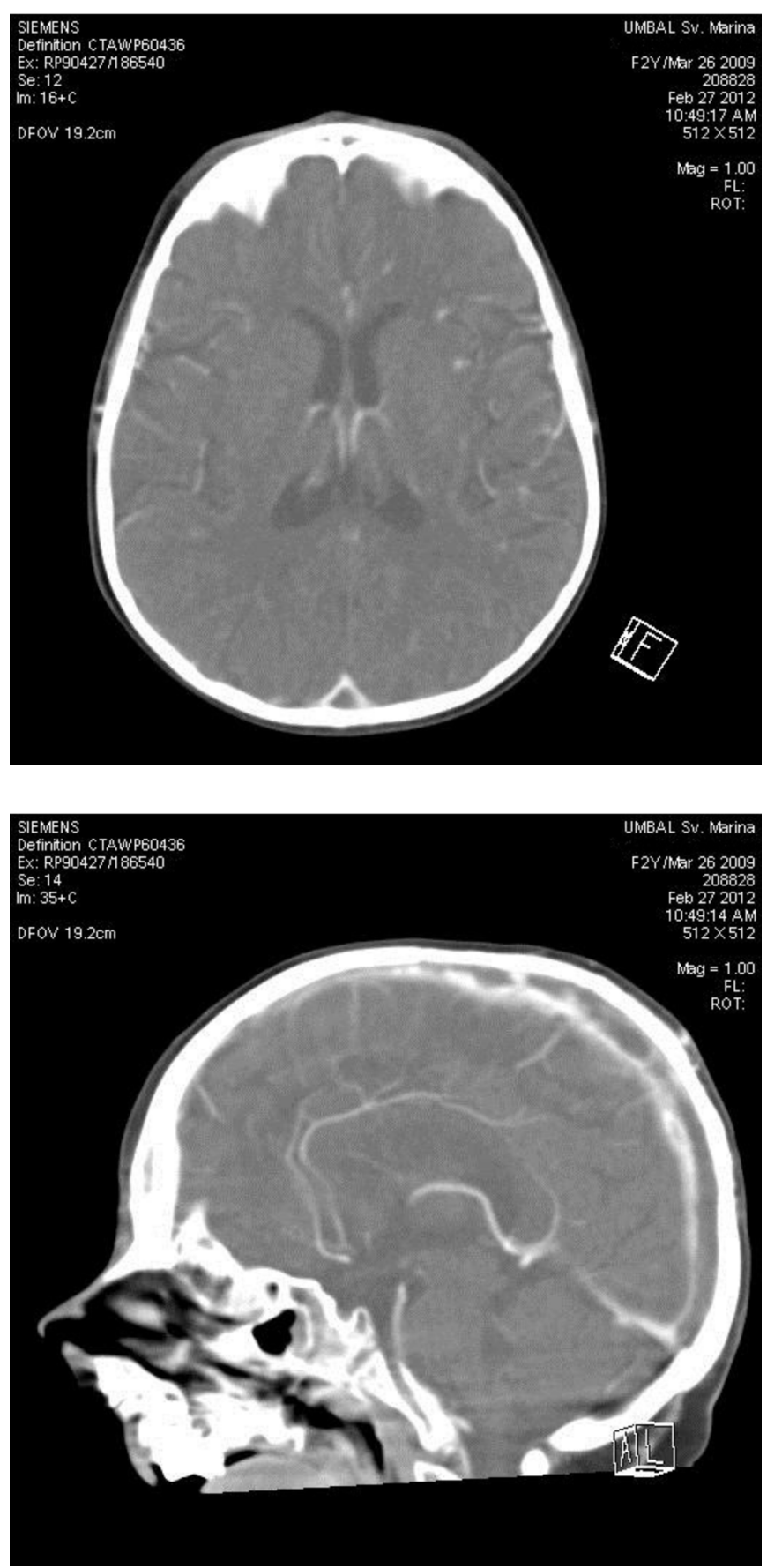

Fig. 3. CTV demonstrated recanalization of right jugular vein, sagittal and right sigmoid sinuses.

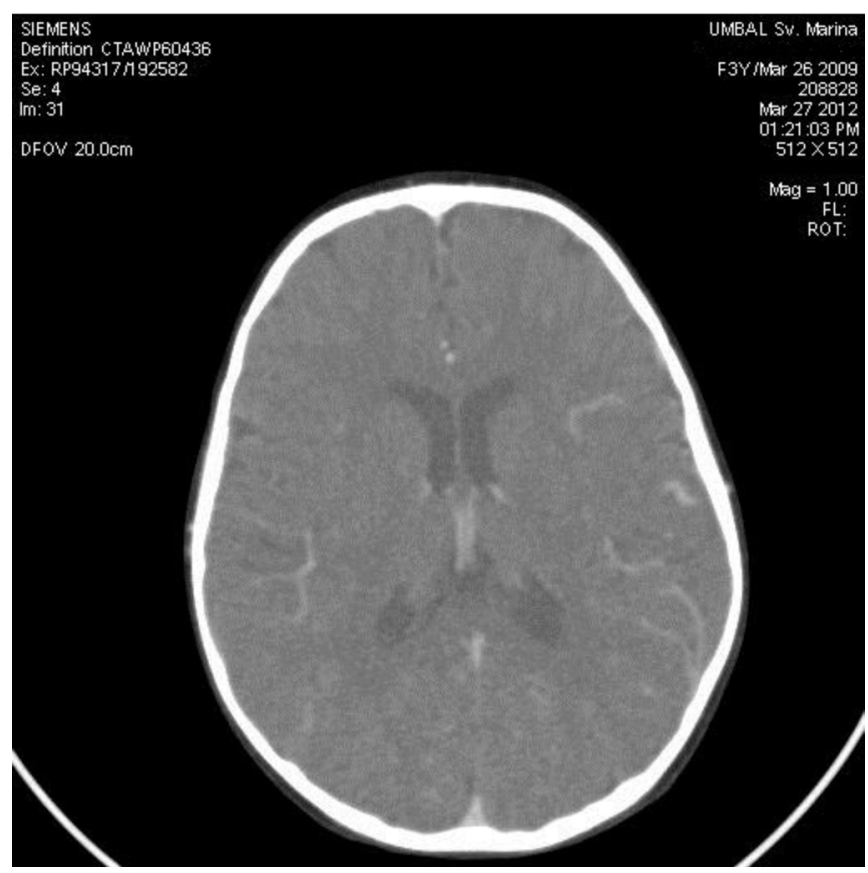

Fig. 4. MRV: disruption of venous flow at the left internal jugular vein, suspecting thrombosis.

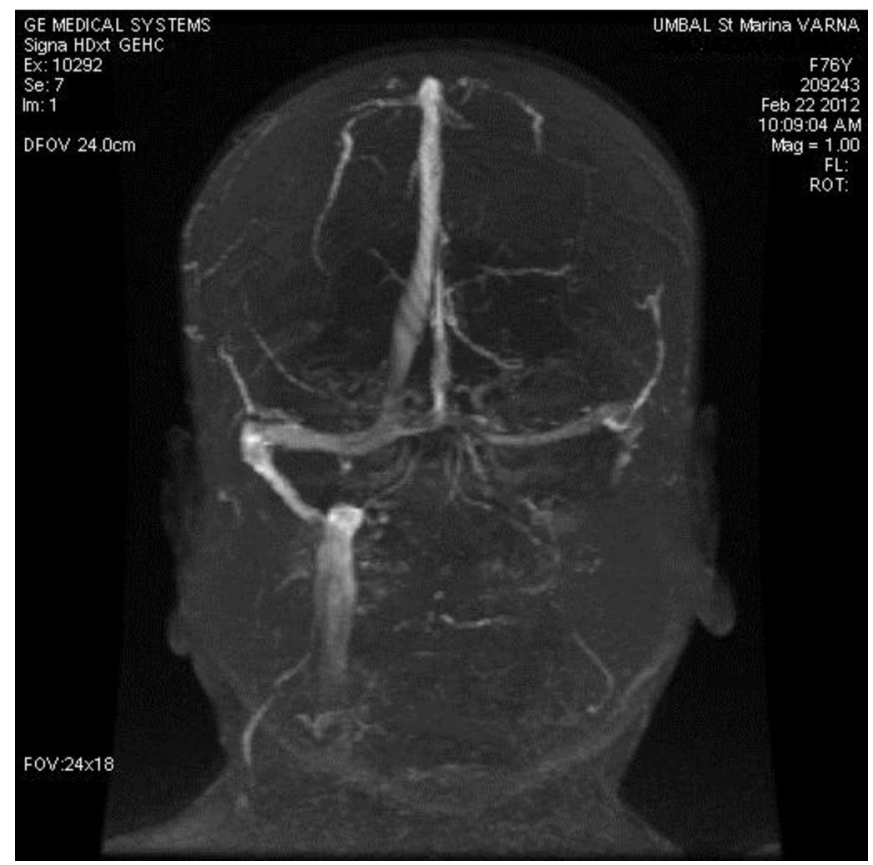


Fig. 5. Extracranial color duplex sonography and CTV: haemodinamic equivalent of left internal jugular vein thrombosis due to selerotic pathology of aortic arch.
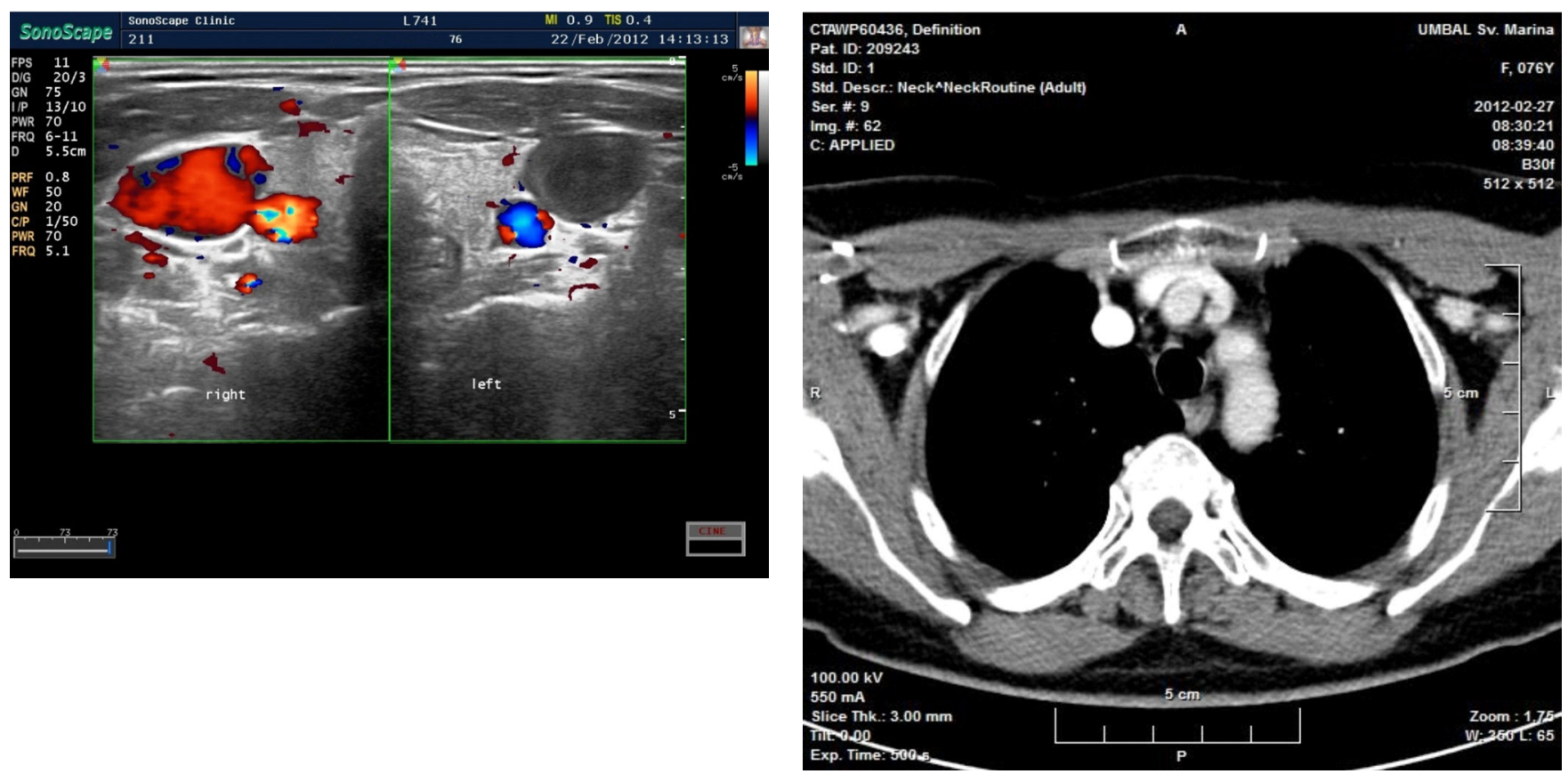

\section{REFERENCES:}

1. Ayanzen RH, Bird CR, Keller PJ, McCully FJ, Theobald MR, Heiserman JE. Cerebral MR venography: normal anatomy and potential diagnostic pitfalls. AJNR Am $J$ Neuroradiol. 2000 Jan;21(1):74-78. [PubMed]

2. Cyriac S, Sagar TG, Shashidhar KV. L-asparginase induced fatal cortical venous thrombosis in acute lymphoblastic leukemia. Indian J Hematol Blood Transfus. 2010 Mar;26(1):8-11. [PubMed] [CrossRef]

3. Dubashi B, Jain A. L-Asparginase induced cortical venous thrombosis in a patient with acute leukemia. J Pharmacol Pharmacother. 2012 Apr-Jun;3(2):194-195. [PubMed] doi: 10.4103/0976-500X.95531.

4. Earl M. Incidence and management of asparginase-associated adverse events in patient with acute lymphoblastic leukemia. Clin Adv Hematol Oncol. 2009 Sep; 7(9):600-606. [PubMed]

5. Fang F, Zou L. Cerebral venous sinus thrombosis. Zhogguo Dang Dai Er Ke Za Zhi. 2006 Jun;8(3):211-215. [PubMed]

6. Foroozan R. Ocular complications of sigmoid sinus thrombosis from Lasparginase. $J$ Pediatr Ophthalmol
Strabismus. 2005 Mar-Apr;42(2):117-119. [PubMed]

7. Goksu E, Akyuz M, Gurkanlar D, Tuncer R. Bilateral abducens nerve palsy following ruptured anterior communicating artery aneurysm: report of 2 cases. Neurocirugia. 2007 Oct;18(5):420-422. [PubMed]

8. Kieslich M, Porto L, Lanfermann H, Jacobi G, Schwabe D, Bцhles H. Cerebrovascular complications of Lasparginase in the therapy of acute lymphoblastic leukemia. J Pediatr Hematol Oncol. 2003 Jun;25(6):484-487. [PubMed]

9. Marzo, S. Sigmoid sinus thrombosis with contralateral abducens palsy: First report of a case. ENT Journal. 2001; 80:869-870. [PubMed]

10. Piatkowska-Jakubas B, KrawczykKuliњ M, Giebel S, Adamczyk-Ciocn, Czyz A, Maracda E, et al. Use of L-asparginase in acute lymphoblastic leukemia: recommendations of the Polish Adult Leukemia Group. Pol Arch Med Wewn. 2008 Nov;118(11):664-669. [PubMed]

11. Pino Rivero V, Pantoja Hernandez C, Gonzales Palomina A, Trinidad Ramos
G, Prado Romero G, Marcos G Garcia M, et al. Internal jugular vein spontaneous thrombosis. Clinical case and review of the literature. An Otorrinolaringol Ibero Am. 2005; 32(6):553-559. [PubMed]

12. Shah V, Yang G, Randhawa S, Hansen M, Lee A. Cerebral venous sinus thrombosis following jugular bulb decompression. Semin Ophthalmol. 2006 Jan-Mar;21(1):41-44. [PubMed] [CrossRef]

13. Shigemori Y, Koshinaga M, Suma T, Nakamura S, Murata Y, Kawamata T, et al. Jugular bulb venous thrombosis caused by mild head injury: a case report. Surg Neurol. 2007 Dec;68(6):660-664. [PubMed] [CrossRef]

14. Stam J. Thrombosis of the Cerebral Veins and Sinuses. N Engl J Med. 2005 Apr 28;352(17):1791-1798. [PubMed] [CrossRef]

15. Watanabe I, Sakai I, Matsumoto I. Superior sagittal sinus thrombosis following L-asparginase therapy of acute lymphoblastic leukemia. Rinscho Ketsueki. 1992 Mar;33(3):343-348. [PubMed]

\section{Address for correspondence:}

Assoc. Prof. Alexandra Tzoukeva, MD, PhD;

Department of Neurology, Medical University of Varna,

55 M. Drinov str, 9002 Varna, Bulgaria; E-mail: al_tz@abv.bg; 